\title{
REVALIDAÇ̃̃O DE MAUESINI (COLEOPTERA, CERAMBYCIDAE, LAMIINAE), TRANSFERÊNCIA DE GÊNEROS, SINONÍMIAS E NOVOS TÁXONS
}

\author{
Carlos Eduardo de Alvarenga Julio ${ }^{1,2}$
}

\begin{abstract}
REVALIDATION OF MAUESINI (COLEOPTERA, CERAMBYCIDAE, LAMIINAE), TRANSFERENCE OF GENERA, NEW SYNONYMS AND NEW TAXA. The tribe Mauesini Lane, 1956 is revalidated (type genus, Mauesia Lane, 1956). The following genera are transferred from Anisocerini to Mauesini: Taurolema Thomson, 1860 and Coroicoia Lane, 1966. New synonyms proposed: Taurolema nasicornis Schwarzer, 1930 with T. albopunctata Gounelle, 1906 and T. lineata Fuchs, 1966 with T. cicatricosa Lane, 1966. New species described from Brazil: Taurolema nigropilosa (Espírito Santo); Mauesia bicornis and M. acorniculata (both from Amazonas). A key to the genera of Mauesini is added.
\end{abstract}

KEYWORDS. Mauesini, Mauesia, Taurolema, taxonomy, Neotropical.

\section{INTRODUÇÃO}

LACORDAIRE (1872) caracterizou a tribo Anisocerini pelas cavidades mesocoxais abertas, garras tarsais divaricadas e pelas mesotíbias com escavação externa. LANE (1956) propôs a subfamília Mauesinae (pois considerava a família Lamiidae), para abrigar Mauesia, assinalando, como caráter que a distinguia de Anisocerini, a condição divergente das garras tarsais. Mais tarde (LANE, 1966) corrigiu-se, já que as garras tarsais são, na realidade, divaricadas. GILMOUR (1965) rebaixou Mauesinae à categoria de tribo e LANE (1973b) a sinonimizou com Anisocerini.

\footnotetext{
1. Departamento de Entomologia, Museu Nacional, Universidade Federal do Rio de Janeiro, Quinta da Boa Vista, São Cristóvão, 20940-040, Rio de Janeiro, RJ, Brasil. (ceajulio@ig.com.br)

2. Doutorando em Ciências Biológicas, Zoologia, Instituto de Biociências, UNESP/Botucatu, São Paulo.
} 
Thomson (1860) estabeleceu o gênero Taurolema para T. bellatrix procedente da Guiana e posicionou-o (1864) na divisão Anisoceritae. As espécies atualmente reconhecidas foram descritas nos trabalhos de Chevrolat (1861), Gounelle (1906, 1908), Schwarzer (1930), LANe (1957, 1966, 1973a) e Fuchs (1966). Segundo MonNé (1994), o gênero está representado por 14 espécies, distribuídas pelas Américas Central e do Sul. Mauesia foi proposto por Lane (1956), para M. cornuta do Amazonas (Brasil) e Coroicoia foi estabelecido por Lane (1966) para Taurolema ligata Schwarzer, 1930, procedente de Coroico (Bolívia), considerando que "diverge de Taurolema, principalmente, pela cabeça subplana, alargada nas genas na : e desarmada no :; pelas antenas sem pincéis ou tufos de pêlos; pela forma mais obcônica do escapo; e pelos élitros de lados subparalelos e mais uniformemente convexos, sem queda abrupta para os lados".

Com base no aspecto das cavidades mesocoxais, das mesotíbias e na presença de uma escavação ventral ovalada provida de pêlos, nos profêmures dos ‘’, é proposta a revalidação da tribo Mauesini e a transferência dos gêneros Taurolema Thomson, 1860, Mauesia Lane, 1956 e Coroicoia Lane, 1966, atualmente alocados em Anisocerini (MonNÉ, 1994).

Apresenta-se uma chave para identificação dos gêneros da tribo e a descrição de três espécies do Brasil, uma em Taurolema (Espírito Santo) e duas em Mauesia (Amazonas). Propõe-se, ainda, as seguintes sinonímias, $T$. nasicornis Schwarzer, $1930=$ T. albopunctata Gounelle, 1906 e T. lineata Fuchs, $1966=$ T. cicatricosa Lane, 1966.

O material examinado pertence às coleções do Museu Nacional, Universidade Federal do Rio de Janeiro (MNRJ) e Museu de Zoologia, Universidade de São Paulo (MZSP). Os diapositivos examinados foram feitos por J. S. Moure, Departamento de Zoologia, Universidade Federal do Paraná (DZUP) no The Natural History Museum, Londres (BMNH) e Muséum National d'Histoire Naturelle, Paris (MNHN).

\section{Mauesini Lane, 1956, revalidada}

Mauesinae Lane, 1956:19; MonNÉ, 1994:1 (em sin. de Anisocerini).

Mauesini; Gilmour, 1965:655 (cat.); Monné, 1994:1 (em sin. de Anisocerini).

Fronte, dos ‘, com cornos mais ou menos desenvolvidos e desarmada nas ; antenas densamente franjadas; antenômero III subigual ao IV em comprimento ou o IV um pouco mais longo. Protórax com tubérculos laterais manifestos e pronoto plano ou com gibosidades discretas; cavidades mesocoxais fechadas. Élitros com pequena elevação centro-basal. Profêmures, dos ‘, com escavação ventral ovalada, mais ou menos desenvolvida, provida de pêlos curtos, eretos; escavação externa das mesotíbias bastante discreta ou ausente e protarsos não-franjados nos :

Por compartilharem os caracteres acima arrolados, os gêneros Taurolema Thomson, 1860, Mauesia Lane, 1956 e Coroicoia Lane, 1966 são transferidos de Anisocerini para Mauesini. 


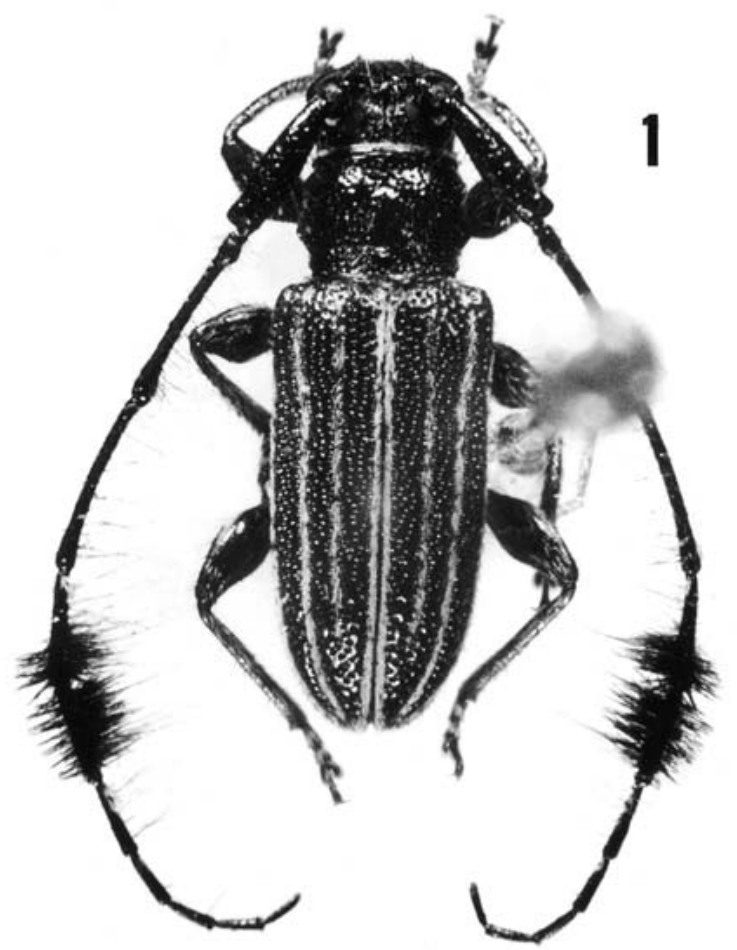

Fig. 1. Taurolema cicatricosa Lane, 1966: ' (MNRJ), Vera, Mato Grosso, Brasil, comprimento 6,6 mm.

Chave para os gêneros de Mauesini

1. Tegumento brilhante; antenas com a pilosidade formando pincéis no lado interno ou tufos ao redor dos antenômeros; escapo fusiforme, finamente pontuado ou cilíndrico, grosseiramente pontuado; mesotíbias sem escavação externa .

Taurolema Thomson, 1860

Tegumento fosco; antenas com a pilosidade formando franjas no lado interno dos antenômeros; escapo clavado ou cilíndrico, finamente pontuado; mesotíbias com discreta escavação externa

2. Cabeça, nos ‘', com escavação pronunciada entre os tubérculos anteníferos; escapo cilíndrico, um pouco espessado para o lado externo do ápice e finamente pontuado; tubérculo lateral do protórax discreto, cônico e afilado no topo; pronoto ligeiramente convexo; élitros planos, sem gibosidade centro-basal; tarsômero III mais longo I + II Mauesia Lane, 1956

Cabeça, nos ‘, não escavada entre os tubérculos anteníferos; escapo clavado; tubérculo lateral do protórax desenvolvido, rombo; pronoto plano; élitros com gibosidade centro-basal manifesta; tarsômero III com comprimento subigual a I + II Coroicoia Lane, 1966 


\section{Mauesia Lane, 1956}

Mauesia LANe, 1956:19; Marinoni, 1977:45; MonNÉ, 1994:15 (cat.).

Espécie-tipo: Mauesia cornuta Lane, 1956 (designação original).

\section{Mauesia bicornis sp. nov.}

(Figs. 3, 6)

Etimologia. Latim, $b i s=$ dois e $\operatorname{cornu}=$ corno, chifre. Alusivo ao aspecto da borda inferior da fronte.

$\therefore$ Tegumento predominantemente amarelo e negro. Cabeça amarela, com um sulco mediano bem marcado, que se estende do centro da fronte até um ponto entre os tubérculos anteníferos. Fronte subplana, lisa, brilhante e com fina pontuação esparsa; borda inferior com dois longos cornos curvos, afastados entre si, afilados e negros no ápice (fig. 6). Tubérculos anteníferos projetados e próximos entre si. Olhos divididos, os lobos oculares superiores pequenos, tão distantes entre si quanto, aproximadamente, quatro vezes a largura de um lobo. Antenas negras, com a base dos antenômeros III-X amarela; longas, ultrapassam os ápices elitrais em três antenômeros, e densamente franjadas, com pêlos longos no lado interno; escapo cilíndrico, um pouco espessado para o ápice, subigual ao IV em comprimento; antenômero III um pouco mais curto, subigual ao V; antenômeros VI-X mais curtos que os anteriores, subiguais em comprimento; o XI mais longo que o precedente e curvo no ápice.

Protórax (fig. 3) amarelo, com tubérculo lateral manifesto pouco atrás do meio e duas faixas longitudinais negras logo abaixo de cada tubérculo. Pronoto esparsa e profundamente pontuado, com duas faixas longitudinais laterais negras que não alcançam a margem anterior; margem posterior bissinuosa. Escutelo amarelo. Élitros negros, com os úmeros, os lados do quarto basal e uma faixa transversal pouco atrás do meio, desde os lados do disco até a sutura, amarelos; disco plano, densa e profundamente pontuado, recoberto por linhas longitudinais de pêlos curtos e eretos; lados subparalelos; ápices arredondados.

Metade basal dos fêmures amarela, a apical negra; fêmures médios pedunculados e posteriores sub-retos. Tíbias negras; protíbias com pequeno alargamento no quarto apical; mesotíbias com escavação externa discreta. Tarsos amarelos.

Abdômen negro; urosternitos subiguais em comprimento.

Dimensões (mm). Comprimento total 7,6-8,5; protórax, comprimento 1,4-1,6, maior largura 2,1-2,3; comprimento do élitro, 5,6-6,1; largura umeral, 2,4-2,7.

Material-tipo. Holótipo ‘, BRASIL, Amazonas: Itacoatiara, IV.1961, Diringshofen col. (MZSP); parátipo ?', Uaupes (Rio Caiary), 1906, H. Schmidt col. (MZSP).

Comentários. Como variações cromáticas, M. bicornis apresenta a região atrás dos lobos oculares superiores negra e, no pronoto, apenas uma faixa central amarela, com o restante do pronoto e os lados do protórax negros. Distingue-se de M. cornuta Lane, 1956 (fig. 4) pelo aspecto da fronte subplana e lisa, com a borda inferior provida de dois longos cornos curvos, afastados entre si e afilados no ápice (fig. 6); pelos tubérculos anteníferos próximos entre si e pela coloração amarela dos úmeros. Em M. cornuta (fig. 4), a fronte apresenta um pequeno espinho ao lado de cada lobo ocular inferior e, partindo 


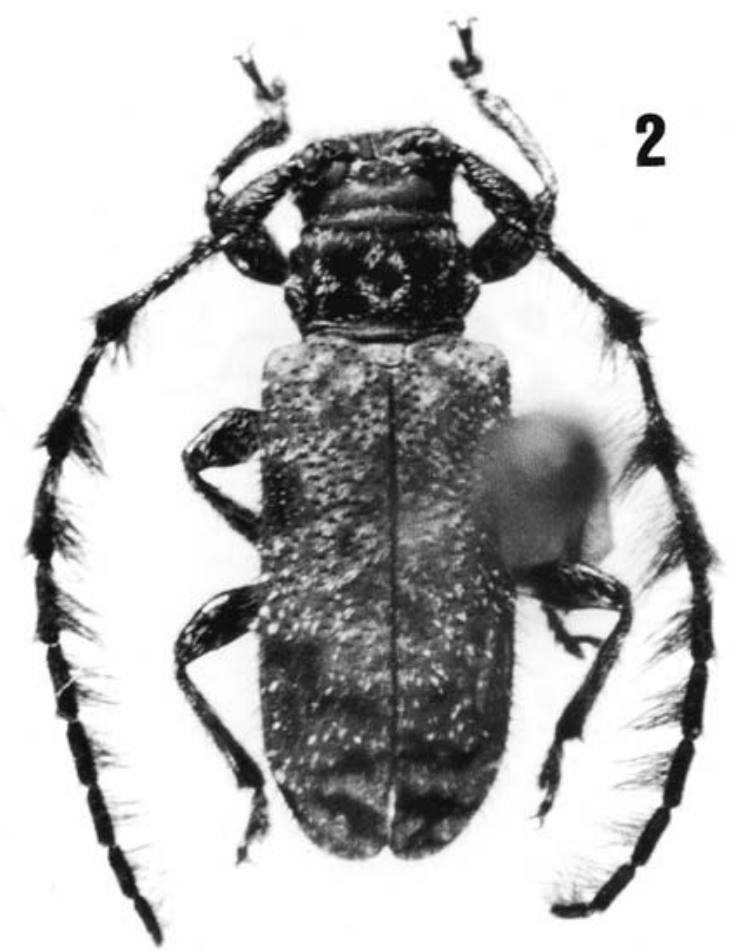

Fig. 2. Taurolema nigropilosa sp. nov.: holótipo - (MNRJ), Conceição da Barra, Espírito Santo, Brasil, comprimento $6,4 \mathrm{~mm}$.

de cada espinho, uma carena curva que se estende até próximo à borda inferior, esta com dois pequenos cornos centrais, eretos e próximos entre si (fig. 7); os tubérculos anteníferos são afastados e os úmeros, negros.

\section{Mauesia acorniculata sp. nov.}

(Figs. 5, 8)

Etimologia. Grego, $a=$ não, sem; latim, corniculatus $=$ cornos. Alusivo ao aspecto da borda inferior da fronte desarmada.

$\therefore$ O padrão cromático é semelhante ao da espécie anterior, com exceção dos lados do protórax que não possuem a faixa longitudinal negra abaixo dos tubérculos e da presença, no escapo, de uma mancha amarela no lado interno da metade apical.

Fronte subplana, lisa, com os lados convergentes para a região inferior, sem carenas ou espinhos; borda inferior reta e desarmada (fig. 8). Lobos oculares superiores tão distantes entre si quanto o dobro da largura de um lobo. Antenas longas, ultrapassam os ápices elitrais em três antenômeros, densamente franjadas, com pêlos longos no lado interno; escapo cilíndrico, um pouco espessado para o lado externo do ápice, subigual em comprimento aos antenômeros III e V; antenômero IV um pouco mais longo; VII-X subiguais, mais curtos que os anteriores; antenômero XI mais longo que o precedente. 
Tubérculo lateral do protórax (fig. 5) discreto, pouco atrás do meio; pronoto esparsamente pontuado apenas sobre a faixa lateral negra. Élitros densa e profundamente pontuados e recobertos por linhas longitudinais de pêlos curtos e eretos; ápices arredondados. Profêmures com a escavação ventral discreta; fêmures médios sub-retos, discretamente pedunculados e posteriores retos; mesotíbias com escavação externa discreta.

Urosternitos subiguais em comprimento.

Dimensões (mm). Comprimento total 6,5; protórax, comprimento 1,2, maior largura 1,7; comprimento do élitro 4,6; largura umeral 2,1.

Material-tipo. Holótipo `', BRASIL, Amazonas: Tabatinga, X.1977, B. Silva col. (MNRJ).

Comentários. Mauesia acorniculata distingue-se das duas outras espécies do gênero pelo aspecto da fronte, sem carenas ou espinhos e a borda inferior desarmada (fig. 8); pela presença, no escapo, de uma mancha amarela no lado interno da metade apical; pelos profêmures com escavação ventral discreta e pelos fêmures médios subretos, discretamente pedunculados. Assemelha-se a M. bicornis, por apresentar os úmeros amarelos.

\section{Taurolema Thomson, 1860}

Taurolema Thomson, 1860:15; 1864:22, 352; Chevrolat, 1861:187; Lacordaire, 1872:727; Gounelle, 1906:11 (rev.); Monné, 1994:13 (cat.).

Espécie-tipo: Taurolema bellatrix Thomson, 1860 (designação original).

\section{Taurolema albopunctata Gounelle, 1906}

Taurolema albopunctata Gounelle, 1906:13; MonnÉ, 1994:13 (cat.).

Taurolema nasicornis Schwarzer, 1930:106, figs. 7, 8; Monné, 1994:13 (cat.). Syn. nov.

O exame do diapositivo do holótipo de T. albopunctata (BMNH), das ilustrações de T. nasicornis e das respectivas descrições originais permitiu propor esta sinonímia.

\section{Taurolema cicatricosa Lane, 1966}

(Fig. 1)

Taurolema cicatricosa LANE, 1966:240; MonNÉ, 1994:13 (cat.).

Taurolema lineata Fuchs, 1966:13; MonnÉ, 1994:13 (cat.). Syn. nov.

O exame do material disponível e do diapositivo do holótipo de T. cicatricosa (BMNH), em confronto com a descrição original de T. lineata, principalmente em relação à coloração, ao aspecto das antenas e dos élitros e à disposição dos tufos de pêlos nos antenômeros permitiu propor a sinonímia entre essas espécies. A prioridade de LANE (1966) justifica-se pelo fato da data de publicação de seu trabalho (18.IV.1966) ser anterior à de FuChs (1966), 30.XII.1966. 

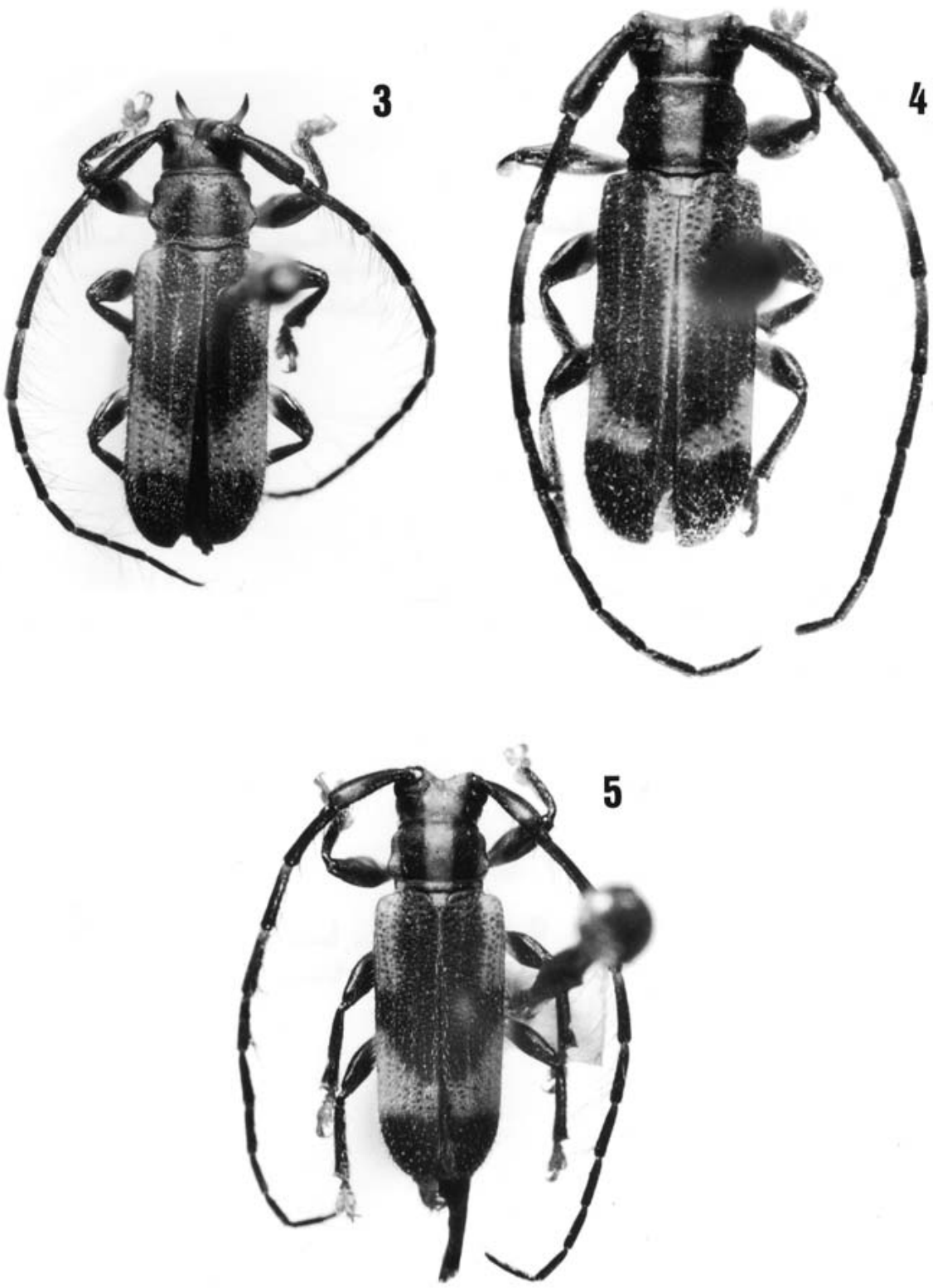

Figs. 3-5. 3, Mauesia bicornis sp. nov.: holótipo ?' (MZSP), Itacoatiara, Amazonas, Brasil, comprimento 7,6 mm; 4, M. cornuta LANe, 1956: holótipo ‘(MNRJ), Maués, Amazonas, Brasil, comprimento 7,5 mm; 5, M. acorniculata sp. nov.: holótipo ' (MNRJ), Tabatinga, Amazonas, Brasil, comprimento $6,5 \mathrm{~mm}$. 
Material examinado. BRASIL, Amazonas: Humaitá, '-, IX.1980, Andrada col. (MNRJ); Manaus (Fazenda Esteio), '-, IX.1984, B.C. Klein col. (MZSP); Tabatinga, -, X.1956, F.M. Oliveira col. (MNRJ); Mato Grosso: Jacaré, - XI.1961, Alvarenga \& Werner cols. (MNRJ); Pontes e Lacerda, 2 '-' X.1990, O. Roppa \& J. Becker cols. (MNRJ); Sinop, '-, X.1974, Roppa \& Alvarenga cols.; '?, X.1975, Roppa \& Alvarenga cols.; ‘, II.1976, Roppa \& Alvarenga cols.; ‘', 3 ', X.1976, Roppa \& Alvarenga cols.; $\iota^{\prime}, 2$, X.1976, B. Silva col. (MNRJ); Vera, '’, 2 ', X.1973, Alvarenga \& Roppa cols. (MNRJ).

\section{Taurolema nigropilosa sp. nov.}

(Fig. 2)

Etimologia. Latim, nigro $=$ negro e pilosus $=$ que possui pêlos. Alusivo ao aspecto da superfície corporal recoberta por pêlos negros.

$\because$ Tegumento predominantemente negro. Genas, occipício e margens anterior e posterior do pronoto avermelhadas; base dos fêmures amarelada. Metatórax e abdômen com reflexos de brilho azul-metálico. Superfície corporal recoberta por pêlos negros eretos; cabeça, escapo, protórax, élitros e pernas com pubescência decumbente branca, curta e esparsa.

Fronte ligeiramente convexa, com a borda inferior reta; região entre os tubérculos anteníferos escavada. Antenas ultrapassam os ápices elitrais em dois antenômeros, densamente pilosas, com pêlos mais concentrados, formando pincéis nos ápices do III e IV e no lado interno dos antenômeros V-XI. Escapo fusiforme, subigual em comprimento aos antenômeros III e IV; III um pouco espessado no ápice; antenômeros V-X subiguais em comprimento; XI um pouco mais longo que o X e curvo no ápice.

Protórax com tubérculo lateral rombo; pronoto plano, sem elevações. Élitros castanho-claros, com manchas laterais negras de contorno irregular, densa e profundamente pontuados na metade basal; gibosidades centro-basais manifestas e ápices arredondados. Fêmures pedunculados; profêmures mais robustos; mesotíbias sem escavação externa.

Urosternito $\mathrm{V}$ com uma pequena depressão centro-apical.

Dimensões (mm). Comprimento total 6,4; protórax, comprimento 0,6, maior largura 1,9; comprimento do élitro 4,7; largura umeral 2,2.

Material-tipo. Holótipo :-, BRASIL, Espírito Santo: Conceição da Barra (Pedro Canário), XI.1972, B. Silva col. (MNRJ).

Comentários. Taurolema nigropilosa assemelha-se a T. flavocincta Gounelle, 1906, por apresentar a região entre os tubérculos anteníferos escavada; pelo escapo fusiforme, tão longo quanto os antenômeros III e IV; pelo protórax com tubérculo lateral e o pronoto plano sem elevações. Distingue-se pelo tegumento dorsal opaco; pelo abdômen com reflexos de brilho azul-metálico; pela superfície corporal densamente recoberta por pêlos negros eretos; pela presença, na cabeça, escapo, protórax, élitros e pernas, de pubescência decumbente branca, curta e esparsa; pela pilosidade das antenas formando pincéis nos ápices dos antenômeros III e IV e no lado interno de V-XI e pelos élitros com gibosidades centro-basais manifestas. Em T. flavocincta: tegumento brilhante; abdômen com brilho castanho-escuro; superfície corporal com pêlos negros esparsos; ausência de pubescência decumbente branca; pilosidade das antenas, ao redor dos antenômeros, formando tufos mais densos nos ápices do III e IV e na metade apical do V; élitros planos, gibosidades centro-basais ausentes. 

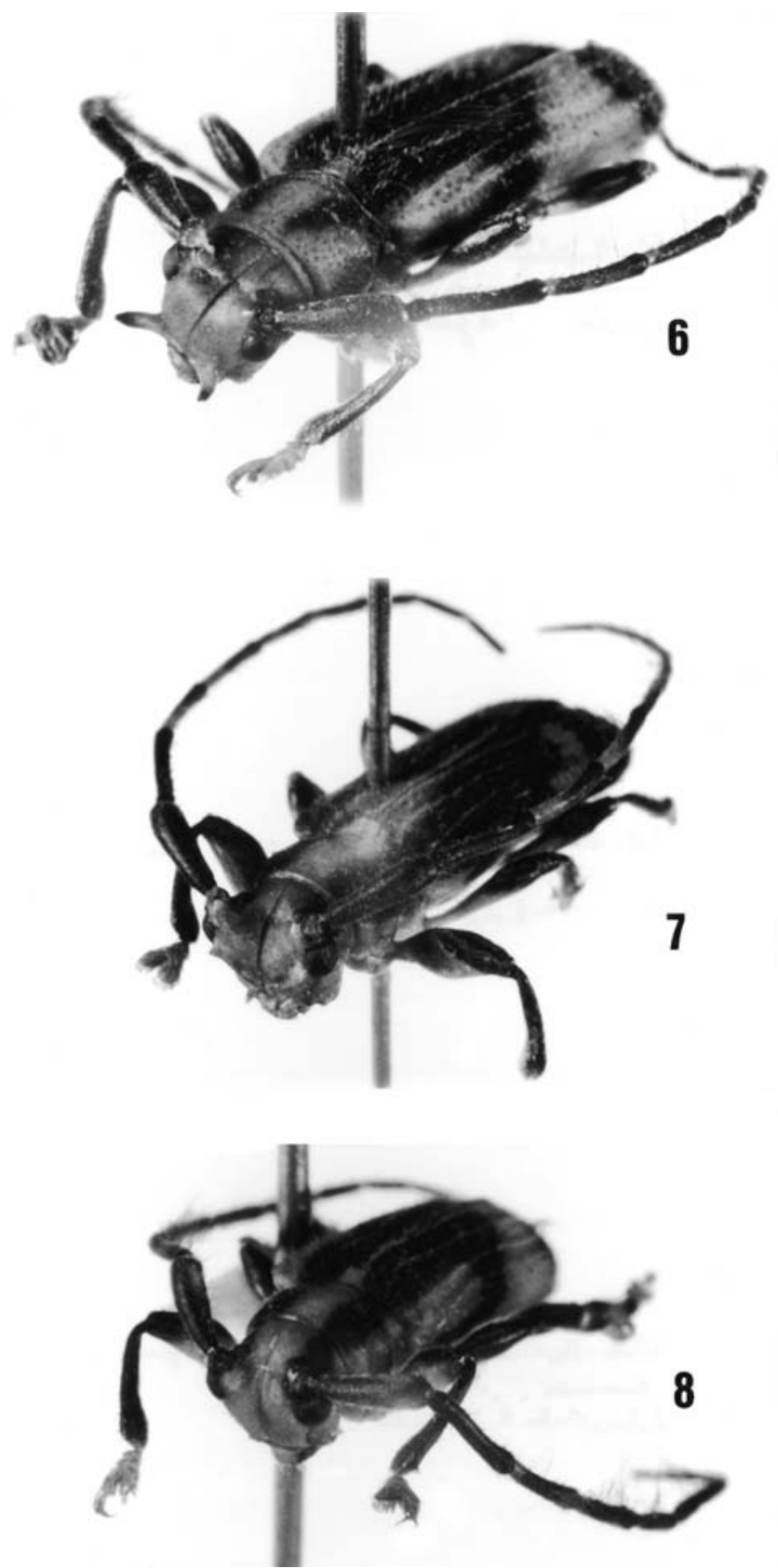

Figs. 6-8. Detalhe da borda inferior da fronte: 6, Mauesia bicornis sp. nov.; 7, M. cornuta Lane, 1956; 8, M. acorniculata sp. nov. 


\section{Coroicoia Lane, 1966}

Coroicoia Lane, 1966:241; Monné, 1994:12 (cat.).

Espécie-tipo: Taurolema ligata Schwarzer, 1930 (designação original).

Coroicoia está representado por apenas uma espécie, C. ligata, procedente de Coroico (Bolívia), estando o holótipo depositado no Forschungs Institut und Naturmuseum Senckenberg, Frankfurt.

Agradecimentos. Ao Dr. Miguel A. Monné (MNRJ) pelas sugestões e revisão do manuscrito; aos Drs. Ubirajara R. Martins (MZSP) e Renato C. Marinoni (DZUP) pelo empréstimo de material e dos diapositivos; a Sérgio Barbosa Gonçalves pela execução das fotografias e a Fundação de Amparo à Pesquisa do Estado de São Paulo (FAPESP, Proc. n 98/10692-5) pela bolsa de Doutorado concedida.

\section{REFERÊNCIAS BIBLIOGRÁFICAS}

Chevrolat, L. A. 1861. Réflexions et notes synonymiques sur le travail de M. James Thomson sur les Cérambycides, avec descriptions de quelques nouvelles espèces. J. Ent., London, 1:185-192.

Fuchs, E. 1966. 7. Beitrag zur Kenntnis der Neotropischen Cerambyciden. Koleopt. Rdsch., Wien, 43-44:9-15.

Gilmour, E. F. 1965. Catalogue des Lamiaires du monde (Col. Cerambycidae). 8. Lieferung, München, Mus. G. Frey. p.559-655.

Gounelle, E. 1906. Cérambycides nouveaux ou peu connus de la région néotropicale principalement de la sous-region brésilienne. Annls Soc. ent. Fr., Paris, 75:1-20.

1908. Cérambycides nouveaux ou peu connus de la région néotropicale, principalement de la sous-région brésilienne. Annls Soc. ent. Fr., Paris, 77:7-20.

Lacordaire, J. T. 1872. Histoire Naturelle des Insectes. Genera des Coléoptères. Paris, Roret, v.9, n. 2, p.411-930.

Lane, F. 1956. Cerambycoidea neotropica nova IV (Coleoptera). Dusenia, Curitiba, 7(1):1-32.

_. 1957. Dos nuevas especies de Anisocerini (Coleoptera, Lamiidae). Neotropica, La Plata, 3(12):65-69.

. 1966. Novos gêneros e espécies de Anisocerini II (Coleoptera, Lamiidae). Pápeis Avuls Zool., São Paulo, 18(20):237-243.

1973a. Cerambycoidea neotropica nova IX (Coleoptera). Studia Ent., Petrópolis, 16(14):371-438.

_. 1973b. Notas sinonímicas VII (Coleoptera, Cerambycidae, Lamiinae). Revta bras. Ent., São Paulo, 17(21):137-143.

Marinoni, R. C. 1977. Some genera of Lamiinae and their type-species. Dusenia, Curitiba, 10(1):37-55.

Monné, M. A. 1994. Catalogue of the Cerambycidae (Coleoptera) of the Western Hemisphere. Part XVII. São Paulo, Sociedade Brasileira de Entomologia. 110 p.

Schwarzer, B. 1930. Beitrag zur kenntnis der Cerambyciden (Ins., Col.). Senckenbergiana, Frankfurt, 12:103-111.

Thomson, J. 1860. Essai d'une classification de la famille des cérambycides et matériaux pour servir a une monographie de cette famille. Paris, Soc. Ent. France. 404 p.

1864. Systema cerambycidarum ou exposé de tous les genres compris dans la famille des cérambycides et familles limitrophes. Mem. Soc. Sci. Liège, Liège, 19:1-540.

Recebido em 15.04.2002; aceito em 28.11.2002.

Iheringia, Sér. Zool., Porto Alegre, 93(1):49-58, 30 de março de 2003 